\section{Outdated listing puts species at risk}

Loopholes could allow illegal wildlife traders and hunters in China to evade prosecution or to receive reduced sentencing. The problem stems from China's Protected Species List (PSL): this has not been updated since it was implemented in 1989, resulting in incongruity with newer taxonomy.

Appendices I and II of the Convention on International Trade in Endangered Species of Wild Fauna and Flora (CITES) and the International Union for Conservation of Nature (IUCN) use taxonomic classifications based on recent revisions to geographical distributions and phylogenetic relationships. Some species that were formerly listed as exotic to China under CITES have had their listing changed to native. But because the PSL has not been revised accordingly, the endemic status of such species is not recognized in law.

For example, the Chinese pangolin (Manis pentadactyla) is on the PSL as a native species. The endangered Malayan and Indian pangolins (Manis javanica and Manis crassicaudata) receive protection as exotic animals under CITES II, but have been endemic to the country since at least 2000. In our view, these species should be added to the PSL immediately to ensure that they have the same protected status as the Chinese pangolin in national legislation. The taxonomic status of leaf monkeys (Trachypithecus spp.) and the Burmese python (Python bivittatus) have also become inconsistent with the PSL, leading to similar risks for these species.

As a result, illegal traders can claim that these animals with biogeographical or name revisions are not on the PSL, even though they may be endangered. To alleviate transborder inconsistencies and aid enforcement, this naming inconsistency issue requires that all 181 signatory nations to CITES adopt unambiguous standardized and internationally coherent naming policies, following the IUCN Red List and CITES Species+ (www. speciesplus.net).

Zhao-Min Zhou* Yunnan Public Security Bureau for Forests,

Kunming, Yunnan, China.

zhouzm81@gmail.com

${ }^{*}$ On behalf of 6 correspondents (see go.nature.com/hubzzy for full list).

\section{Physicists' report on EU green electricity}

The European Physical Society has released a report on European Union (EU) plans for sustainable production of green electricity in the context of today's global energy and climate challenges (see go.nature.com/2blxp9). The report advises Europe to develop a common energy policy that could act as a template for other regions.

It points out that Europe's contribution to global greenhouse-gas emissions is relatively low, so producing electricity without fossil fuels would cut global emissions by a mere 3-4\%. Any plans for worldwide green electricity structures would need to address problems such as intermittency and storage, and the need for backup systems and large, high-capacity electrical grids.

The report suggests that energy targets should be scientifically justifiable and adjusted to be more realistic. This would reduce the cost of enforcing the targets through regulation and encourage competition in EU industry. A common policy is needed for implementing those regulations, the report emphasizes.

It also recommends that the public should have access to scientific information on energy issues rather than to simplified plans and projections, and it urges Europe to continue to lead the way in cutting greenhousegas emissions.

Jozef Ongena Laboratory for Plasma Physics, Royal Military Academy, Brussels, Belgium. Christophe Rossel European Physical Society, Mulhouse, France.

j.ongena@fz-juelich.de

\section{Laboratory seawater studies are justified}

In our view, your report

'Seawater studies come up short' (Nature 524, 18-19; 2015) fails to capture the nuances of the survey results you discuss (see C. E. Cornwall and C. L. Hurd ICES J. Mar. Sci. http://doi. org/68g; 2015).

Researchers aim to follow the 2010 'Guide to best practices for ocean acidification research and data reporting' (go.nature. com/sp5kgn) as they strive to understand how marine organisms are likely to respond to the falling $\mathrm{pH}$ of the world's oceans, caused by increased carbon dioxide concentrations. The logistical constraints of testing the effects of seawater acidification on marine life in the laboratory are considerable. However, experiments must be replicated while complying with the requirements for manipulating and monitoring seawater carbonate chemistry.

The paper, co-authored by two of us, does not conclude from its meta-analysis of such manipulation experiments that all these studies "come up short". Rather, it uses them to highlight the importance and challenges of proper experimental design for such testing. The examples of experimental pitfalls it cites are intended not as criticisms, but to guide future efforts.

Together with palaeo-record investigations, modelling studies and natural and manipulated field experiments, we believe that laboratory experiments are crucial to the mechanistic understanding and prediction of ocean-acidification impacts. Catriona L. Hurd ${ }^{\star}$ Institute for Marine and Antarctic Studies, University of Tasmania, Australia.

catriona.hurd@utas.edu.au ${ }^{\star}$ On behalf of 7 correspondents (see go.nature.com/vucoxr for full list).

\section{More extensive tests for e-cigarettes}

We are concerned that the focus on nicotine in electronic cigarettes is causing other associated risks to be underestimated (see Nature 523, 267; 2015).

For example, there are no moves to evaluate the chemical hazards attributable to the non-nicotine components of e-cigarettes, such as vaporizing solvents or liquid 'flavourings' - let alone to regulate them. Neither will the latest European legislation on tobacco and related products help (see go.nature.com/yufgfv). It does not cover liquids or devices that are branded as 'nicotine-free': however, these frequently contain nicotine and escape safety testing through erroneous labelling (see C. Hutzler et al. Arch. Toxicol. 88, 1295-1308; 2014).

Electronic vaping could also offer a route for using drugs such as cannabis (A. J. Budney et al. Addiction http://doi. org/7cc; 2015). With the technology set to evolve and spread rapidly, more rigorous and extensive evaluation is urgently needed.

Frank Henkler, Andreas Luch German Federal Institute for Risk Assessment (BfR), Berlin, Germany. andreas.luch@bfr.bund.de

CONTRIBUTIONS

Correspondence may be submitted to correspondence@nature. com after consulting the author guidelines at http:// go.nature.com/cmchno. 